\title{
Spontaneous Perforation of Stomach in a Neonate
}

\author{
Sethi $\mathrm{H}^{1}$, Simalti $\mathrm{A}^{2}$, Chauhan $\mathrm{SS}^{3}$, Chandra $\mathrm{M}^{4}$
}

\begin{abstract}
Spontaneous gastric perforation is not a very common entity. If not suspected and managed in time, this is uniformly fatal. Although documented as early as in1825 exact pathology remains unclear even to date. A case of spontaneous rupture in a term neonate is being presented as a case report.
\end{abstract}

Key words: Gastric perforation

\section{Introduction}

$S^{\mathrm{p}}$ pontaneous gastric perforation of the newborn is an uncommon entity $^{1}$. Although the condition entails a very high mortality, its pathogenesis is still not universally agreed upon ${ }^{2}$. Many factors have been postulated to explain the aetiopathogenesis of this disease, and all of these occur in individual cases. We report a case of spontaneous gastric perforation seen by us in a three-day-old neonate.

\section{The Case}

A three day old female baby was brought with history of blood stained stool. Baby was born at term with no significant antenatal history. Baby was found to be lethargic on examination. Systemic examination revealed abdominal distention and absent bowel sounds. Abdominal X-ray showed free intraperitoneal air (Fig 1). The provisional diagnosis was perforative peritonitis. On exploration, after opening the lesser sac there was a $2 \mathrm{~cm} \times 1.5 \mathrm{~cm}$ perforation seen on the posterior wall along the greater curvature, with inflammatory exudates all over the abdominal cavity. Primary repair was done in two layers and abdomen was closed. A drain was left in place. Postoperative period was uneventful and baby was discharged on $15^{\text {th }}$ postoperative day. Histopathology of the margin of perforation area revealed nonspecific inflammation which did not lead to any specific aetiology of perforation in our case.

\section{Discussion}

First reported case of spontaneous rupture of the stomach in the newborn was in 1825 by Siebold ${ }^{3}$ and first reported survival of an infant was reported in $1950^{4}$. Spontaneous gastric perforation is more
'Dr Harish Sethi, MBBS, MD, Military Hospital Amritsar, India. ${ }^{2}$ Dr. Ashish Simalti, MBBS, MD,FNB, Base Hospital, Delhi Cantt, India. ${ }^{3}$ Dr SS Chauhan, MBBS, MS,.DNB, MNAMS, FICS(Gastro) Base hospital Delhi Cantt India. ${ }^{4} \mathrm{Dr}$ Mukesh Chandra, MBBS,MD, Base Hospital, Delhi Cantt, India.

\section{Address for correspondence: \\ Dr. Ashish Simalti \\ E-mail; ashishsimalti@rediffmail.com}

\section{How to cite}

Sethi H, Simalti A, Chauhan SS, Chandra M. Spontaneous Perforation of Stomach in a Neonate. J Nepal Paediatr Soc 2015;35(3):301-303.

doi: http://dx.doi.org/10.3126/jnps.v35i3.11885

This work is licensed under a Creative Commons Attribution 3.0 License.

(c) (7)

common in preterm babies ${ }^{2}$. Perforations most commonly occur between the 2 nd and 7th days of age, most commonly on the 3 rd day of life ${ }^{5}$. Our baby was a full term baby and the perforation had occurred on third day of life.

The incidence of prenatal and perinatal risk factors is reportedly high. Besides prematurity other reported risk factors include birth asphyxia requiring resuscitation, premature rupture of membranes, breech, Cesarean or twin delivery, in decreasing order of frequency ${ }^{2}$. Necrotizing enterocolitis, and postnatal steroid usage have also been reported as risk factors ${ }^{6,7}$. However spontaneous gastric perforation has also been reported in term infants without apparent risk factors as was the case with this baby ${ }^{8}$. 


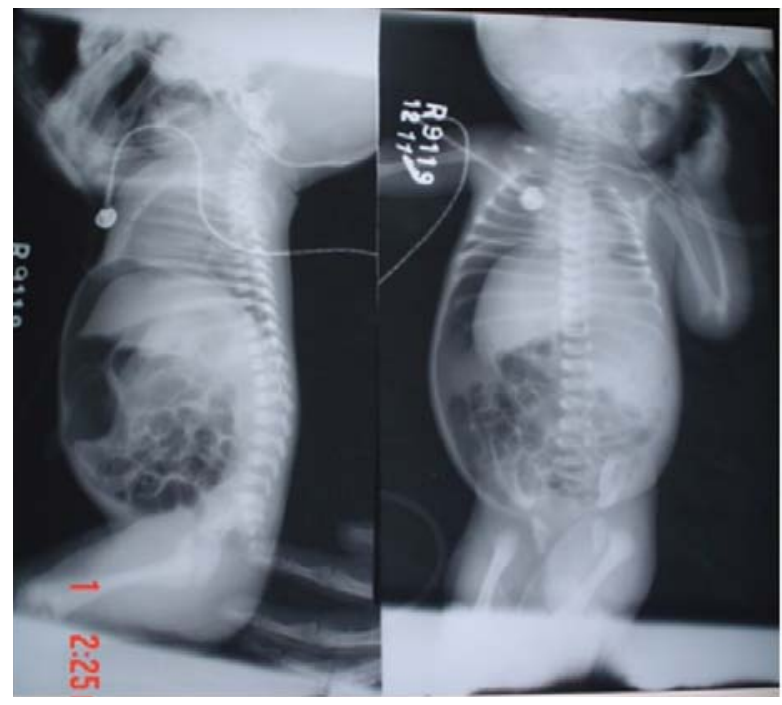

Fig 1: X-Ray; kiddigram showing free gas under the right hemidiaphragm delineating the right margin of the liver on the anteroposterior view. The gas is seen subjacent to the anterior abdominal wall on the lateral view. Findings are suggestive of pneumoperitoneum secondary to perforation of a hollow intra-abdominal viscus.

The pathogenesis of spontaneous gastric perforation is much debated. Anatomical defects of the gastric muscular wall have been suggested to potentiate perforation of the stomach among neonates, especially in prematurity ${ }^{7}$. The circular muscle layer of the newborn stomach normally contains several gaps, most prominently in the fundus, near the greater curvature. These gaps are more common in premature infants. Gastric tissue ischemia secondary to hypoxia is another plausible explanation ${ }^{2}$. During severe hypoxic stress there is diving reflex causing selective shunting of blood away from the splanchnic vascular bed. Traumatic neonatal gastric perforation is usually iatrogenic caused by interventions such as gastric tube insertion or attempted intubation.

Sudden abdominal distension and respiratory distress have been the reported predominant symptoms besides various combination of, feeding intolerance, respiratory distress, or poor activity ${ }^{9}$. The most common radiographic finding in gastric perforation is pneumoperitoneum, which in this case is obvious, and significant enough to cause elevation of the diaphragms and subsequent compression of the lungs. Subtle radiographic findings of pneumoperitoneum include the "football sign," when the falciform ligament is seen as a dense, vertical, near-central strip surrounded by gas, the "saddle bag" sign, where the liver and spleen are displaced downwards and towards midline, and the "arcade" sign, where air is seen between bowel loops, forming extralumenal triangular shaped areas of gas ${ }^{10}$.
Surgical repair of most perforation consists of debridement and two layer closure of stomach. Significant gastric resection should be avoided but cases have been reported where significant part of stomach was removed ${ }^{11}$. Post operative intensive care is crucial for survival and includes empiric broad spectrum antibiotic cover. In very sick infants, shortterm external peritoneal drainage may be required, followed by formal surgical repair of the perforation once the infant's condition is stabilized. Due to the associated problems of sepsis and respiratory failure often found in premature infants, mortality rates of gastric perforation are high, ranging from $45 \%$ to $58 \%{ }^{10}$. For better outcome, interval between the onset of symptoms and start of definitive therapy should be minimized.

\section{Conclusion}

Regardless of cause, a timely diagnosis of gastric perforation must be made and surgical correction is performed expediously to prevent significant morbidity. Aim of presenting this case report was to generate awareness about this potentially catastrophic event which can happen even in a neonate without any apparent risk factors.

\section{References}

1. Houck WS, Griffin JA. Spontaneous linear tears of the stomach in the newborn infant. Ann Surg 1981, 193: 763-7.

2. Gathwala G, Rattan K.N., Abrol P, Sodhi D.Spontaneous Gastric Perforation in a Neonate. Indian Pediatr 1994,31:1013-5.

3. Linkner L M., Benson C D. Spontaneous Perforation of the Stomach in the Newborn: Analysis of Thirteen Cases. Ann Surg 1959;149:4,525-33.

4. Leger JL, Ricard PM, Leonard C, Piette J. Ulcère gastrique perforé chez un nouveau-né avec survie. Union Méd. Canada 1950;79:1277-80.

5. Ryckman FC. Selected anomalies and intestinal obstruction. In: Avery A, Fanarof AA, Richard J, Martin RJ, editors. Neonatal perinatal medicine diseases of the fetus and infant. 7 th ed. USA: Mosby; 2002. p. 1283.

6. Stark AR, Carlo WA, Tyson JE, Paile LA, Wright LL, Shankaran S, et al. Adverse Effects of Early Dexamethasone Treatment in Extremely-LowBirthWeight Infants. N Engl J Med 2001;344:95101. 
7. Grosfeld JL, Molinari F, Chaet M, Engum SA, West KW, Rescorla FJ, et al. Gastrointestinal perforation and peritonitis in infants and children: Experience with 179 cases over ten years. Surgery 1996;120:650-56.

8. Kshirsagar AY, Vasisth GO, Ahire MD, Kanojiya RK, Sulhyan SR. Acute spontaneous gastric perforation in neonates: A report of three cases. Afr J Paediatr Surg 2011;8:79-81.
9. Hara S, Crump EP. Spontaneous Rupture of the Stomach in the Newborn: A Report of Six Cases in Negro Infants and a Review of the Literature. J Natl Med Assoc 1962;54(6):689.

10. Chouteau W, Green D W. Neonatal gastric perforation. J Perinatol 2003;23:345-47.

11. Rosser SB, Clark CH, Elechi EN. Spontaneous neonatal gastric perforation. J Pediatr Surg 1982;17:390-94. 